\title{
Composição química e alterações estruturais do arroz irrigado durante $o$ armazenamento
}

\section{Chemical composition and structural changes of irrigated rice during storage}

\author{
Tiago André Kaminski ${ }^{1}$; Auri Brackmann²; Leila Picolli da Silva²; \\ Ana Betine Beutinger Bender ${ }^{3 *}$; Caroline Sefrin Speroni ${ }^{4}$
}

\section{Resumo}

O efeito do tempo de armazenamento em diferentes temperaturas $\left(0,5 ; 20\right.$ e $\left.35^{\circ} \mathrm{C}\right)$ foi avaliado sobre a composição química, capacidade de elongação e propriedades viscoamilográficas de três variedades de arroz irrigado (BR-IRGA 410, IRGA 416 e IRGA 417), durante 180 dias. As alterações nos componentes dos grãos polidos foram significativas $(\mathrm{P}<0,05)$ para o teor de matéria mineral, compostos fenólicos, amilose e amido resistente, com incrementos nos valores encontrados, principalmente em maiores períodos e temperaturas de armazenamento. As variáveis do experimento (variedade do arroz irrigado, tempo e temperatura do armazenamento) influenciaram significativamente $(\mathrm{P}<0,01)$ nos parâmetros de elongação dos grãos, com aumentos expressivos durante o armazenamento a $35^{\circ} \mathrm{C}$ e nas propriedades viscoamilográficas, ou seja, observou-se maior viscosidade, resistência à quebra e retrogradação para as amostras com maior teor de amilose e mantidas a $35^{\circ} \mathrm{C}$ durante o armazenamento. As alterações nos componentes dos grãos, quando significativas $(\mathrm{P}<0,05)$, foram bastante discretas e não diretamente relacionadas às significativas alterações $(\mathrm{P}<0,01)$ de elongação e viscosidade. A temperatura se mostrou uma variável de grande influência no processo de envelhecimento do arroz, sugerindo a possibilidade do armazenamento deste cereal em maiores temperaturas para conferir qualidade culinária em menor tempo de armazenamento.

Palavras-chave: Envelhecimento, lipídios, amilose, elongação, viscosidade

\begin{abstract}
The effect storage time at different temperatures $\left(0.5,20\right.$ and $\left.35^{\circ} \mathrm{C}\right)$ was periodically evaluated in regard to the chemical composition, elongation capacity and viscoamylographic properties of three irrigated rice varieties (BR-IRGA 410, IRGA 416 and IRGA 417) during 180 days. The alterations in the components of the polished grains were significant $(P<0.05)$ for the content of ash, phenolic compounds, amylose and resistant starch, with increments in the found values, mainly after longer periods and at higher storage temperatures. The experiment variables (irrigated rice variety, temperature and storage time) in the elongation parameters of the grains influenced significantly $(P<0.01)$, with expressive increases during the storage at $35{ }^{\circ} \mathrm{C}$ and the viscoamylographic properties, in other words, observed greater viscosity, resistance to breakdown and setback for the samples with higher content of amylose stored during storage at $35{ }^{\circ} \mathrm{C}$. The alterations in the components of the grains, when significant $(P<0.05)$, were quite discreet and do not direct related to the significant alterations $(P<$
\end{abstract}

\footnotetext{
${ }^{1}$ Farmacêutico, M.e. em Ciência e Tecnologia dos Alimentos, Doutorando em Ciência e Tecnologia dos Alimentos da Universidade Federal de Santa Maria, UFSM, Santa Maria, RS. E-mail: tiagoandrekaminski@hotmail.com

${ }^{2}$ Eng $^{\text {os }}$ Agr ${ }^{\text {ss, }}$ Profs. Drs. da UFSM, Santa Maria, RS. E-mail: brackman@ccr.ufsm.br; leilasliva@yahoo.com.br

${ }^{3}$ Farmacêutica, UFSM, Santa Maria, RS. E-mail: betinebender@hotmail.com

${ }^{4}$ Discente de Graduação em Química, UFSM, Santa Maria, RS. E-mail: carolinesperoni@gmail.com

* Autor para correspondência
} 
$0.01)$ in elongation and viscosity. The temperature turned out to be a variable of great influence in the rice ageing process, suggesting the possibility of storing this cereal in higher temperatures in order to provide culinary quality in a shorter period of storage.

Key words: Ageing, lipids, amylose, elongation, viscosity

\section{Introdução}

O arroz faz parte dos hábitos alimentares dos brasileiros há mais de um século, sendo consumido principalmente na forma de grãos descascados e polidos, que no processo de beneficiamento têm o endosperma separado, parcial ou totalmente, do embrião e da película (NAVES, 2007).

O processo de beneficiamento, particularmente o polimento, representa perdas de aproximadamente $10 \%$ de peso do grão integral e considerável diminuição dos nutrientes das camadas externas, mas outros fatores também influenciam no valor nutricional do arroz. Tais variáveis estão relacionadas com as condições de cultivo (temperatura, umidade, radiação solar, natureza do solo e adubação) e com as formas de preparo do cereal para consumo. Dentre os componentes do arroz, as proteínas e micronutrientes são os mais alterados pelas condições de cultivo (MARSHALL; WADSWORTH, 1994).

Além do valor nutricional, o consumidor de arroz está cada vez mais exigente em relação às características sensoriais deste cereal, sendo que a qualidade culinária é o fator determinante na aceitação do produto, que deve apresentar grande capacidade de absorção de água, aumento volumétrico, elongação e soltabilidade dos grãos (BASSINELLO; ROCHA; COBUCCI, 2004; FARUQ et al., 2003).

Embora o arroz seja consumido de diversas formas, como em doces, salgados, saladas ou ingrediente de formulações na forma de farinha, o consumo mais representativo ainda corresponde ao preparo isolado do arroz polido, apenas com sal, óleo e água, onde o arroz com grãos soltos após cozidos é preferência dos brasileiros (BASSINELLO. ROCHA; COBUCCI, 2004; ELIAS, 2007).
Mesmo estabelecendo uma relação entre alguns componentes do grão com a qualidade culinária do arroz, diversos trabalhos relatam que independente da composição química dos grãos, as características culinárias só são alcançadas após um período de armazenamento, no qual ocorre o envelhecimento do arroz, que envolve mudanças nas propriedades físico-químicas dos grãos (SODHI et al., 2003; ZHOU et al., 2002).

Desta forma, este trabalho teve por objetivo avaliar periodicamente o efeito do tempo de armazenamento em diferentes temperaturas $\left(0,5 ; 20\right.$ e $\left.35^{\circ} \mathrm{C}\right)$ sobre a composição química, capacidade de elongação dos grãos e propriedades viscoamilográficas de três variedades de arroz irrigado (BR-IRGA 410, IRGA 416 e IRGA 417).

\section{Materiais e Métodos}

Condução do experimento: Três variedades de arroz em casca (BR-IRGA 410, IRGA 416 e IRGA 417), cultivadas em sistema irrigado por alagamento na Estação Experimental do Arroz (EEA) do Instituto Rio Grandense do Arroz (IRGA) (295' $\mathrm{S}$ e $\left.51^{\circ} 06^{\prime} \mathrm{O}\right)$, safra 2010/2011, foram coletadas imediatamente após a secagem por método intermitente. As amostras foram subdivididas em frações de aproximadamente 1 $\mathrm{kg}$, fechadas em sacaria de algodão, identificadas e acondicionadas aleatoriamente em câmaras herméticas com diferentes temperaturas controladas em 0,$5 ; 20$ e $35^{\circ} \mathrm{C}$ no Núcleo de Pesquisa em PósColheita da Universidade Federal de Santa Maria. As amostragens e análises foram realizadas nos intervalos de 30,60, 90, 120, 150 e 180 dias após o início do armazenamento em três repetições.

Beneficiamento do arroz: Em máquina testadora de arroz (MT, Suzuki), cerca de $100 \mathrm{~g}$ de arroz foi 
descascado, polido e classificado em cada operação. Os grãos de arroz polido remanescentes no trieur (inteiros) e no cocho (quebrados) foram pesados para cálculo do rendimento em porcentagem, sendo reservados apenas os grãos inteiros para a sequência de análises.

Moagem e peneiramento: Os grãos inteiros obtidos no beneficiamento do arroz foram moídos em micromoinho (MA-630, Marconi) e as frações moídas foram peneiradas através de peneira com abertura de $300 \mu \mathrm{m}$.

Composição centesimal: Foram determinados o teor de umidade, matéria mineral, proteína bruta e fibra alimentar de acordo com métodos analíticos propostos pela AOAC (2000). Os lipídios foram quantificados pelo método descrito por Bligh e Dyer (1959) e o teor de carboidratos estimado a partir da diferença de 100 menos os demais parâmetros analisados, citados anteriormente.

Compostos fenólicos: Os compostos fenólicos solúveis totais foram extraídos das amostras por uma metodologia modificada a partir de Iqbal, Bhanger e Anwar (2005) e Pérez-Jiménez e SauraCalixto (2005). As amostras foram sucessivamente homogeneizadas em metanol 80\% (diluído com água ultrapura), metanol $80 \%$ pH 2,0 ( $\mathrm{pH}$ corrigido com $\mathrm{HCl}$ concentrado) e acetona $70 \%$, seguidas por etapas de agitação (por 1 hora em agitador de tubos), centrifugação (durante 10 minutos a $3000 \mathrm{rpm}$ ) e separação do sobrenadante. Os sobrenadantes de cada etapa foram homogeneizados e utilizados como extrato. A concentração dos compostos fenólicos extraídos foi avaliada pela metodologia de Singleton, Orthofer e Lamuela-Raventós (1999), a partir da diluição de uma alíquota do extrato, adição do reagente Folin-Ciocalteu 0,25 mol.L $\mathrm{L}^{-1}$ e solução de carbonato de sódio 7,5\%, incubação por 2 horas no escuro e medição da absorbância em espectrofotômetro (SP-220, Bioespectro) a $765 \mathrm{~nm}$. Na confecção da curva padrão foi utilizado o ácido gálico e os resultados expressos em equivalente de ácido gálico (EAG) por $100 \mathrm{~g}$ de amostra (base seca).
Amido: As frações de amido disponível e resistente foram avaliadas conforme método enzimático descrito no protocolo 996.11 da AOAC (2000), observando as modificações propostas por Walter, Silva e Perdomo (2005).

Amilose: Os teores de amilose foram determinados de acordo com a técnica iodométrica descrita por Martínez e Cuevas-Perez (1989), que compreende etapas de dissolução da amostra, gelatinização do amido, acidificação e complexação da amilose pela adição de solução de iodo, possibilitando a leitura da intensidade de coloração azul em espectrofotômetro a $620 \mathrm{~nm}$.

Elongação: Com o auxílio de um paquímetro digital (MIP/E-103, Mitutoyo) foram mensurados o comprimento $(C)$ e a largura (L) de dez grãos de arroz crus e após cozidos pela metodologia descrita por Bassinello, Rocha e Cobucci (2004). A partir das médias das medições foram calculados os parâmetros propostos por Sood e Siddiq (1980):

- Alteração proporcional $=[(\mathrm{C}$ cozido $/ \mathrm{L}$ cozido $)$ $-(\mathrm{C}$ cru/L cru $)]$ / (C cru/L cru $)$

- Taxa de elongação $=\mathrm{C}$ cozido $/ \mathrm{C}$ cru

- Elongação efetiva $=\mathrm{C}$ cozido $-\mathrm{C}$ cru

Análise de RVA (Rapid Viscoanalysis): As propriedades viscoamilográficas foram determinadas através do equipamento Rapid Visco-Analyzer (RVA3D+, Newport Scientific) e de acordo com o método padrão 61-02 da AACC (2000), obtendo-se os parâmetros de temperatura de pasta $\left({ }^{\circ} \mathrm{C}\right)$, viscosidade de pico (RVU), tempo de pico (minutos), quebra (RVU), retrogradação (RVU) e viscosidade final (RVU).

Análise estatística: Em programa Statistical Package for Social Sciences (SPSS) 8.0 para Windows, os dados de rendimento, elongação e RVA foram submetidos à análise de variância (ANOVA) e comparados pelo teste de Tukey a nível de $1 \%$ de significância para as interações das variáveis do experimento (variedade, temperatura e tempo de armazenamento do arroz). As médias 
dos parâmetros com interações significativas entre as variáveis foram dispostas graficamente em função do tempo de armazenamento, com linha de tendência e equação da reta ou função, observando coeficiente de determinação $\left(\mathrm{R}^{2}\right)$ mínimo de 0,7 . Os resultados da composição química dos grãos também foram submetidos à análise de variância e comparados pelo teste de Tukey em nível de 5\% de significância, porém tabelados para comparação das médias dos diferentes períodos e temperaturas de armazenamento de cada variedade de arroz.

\section{Resultados e Discussão}

No beneficiamento das amostras não foram evidenciadas alterações significativas $(\mathrm{P}>0,01)$ no rendimento de grãos inteiros e quebrados durante o período do experimento, com médias de 58,5 X 10,$5 ; 61,2$ X 7,9 e 62,1 X 7,2 em porcentual de grãos inteiros $\mathrm{X}$ quebrados para $100 \mathrm{~g}$ de arroz em casca das variedades BR-IRGA 410, IRGA 416 e 417, respectivamente. Estas diferenças entre as variedades mantiveram-se por 180 dias, independente da temperatura de armazenamento.

Conforme resultados da Tabela 1, as variedades avaliadas no decorrer do período de armazenamento apresentaram teores de minerais variando entre 0,33 e $0,47 \%$ da matéria seca do arroz polido. Significativas alterações $(\mathrm{P}<0,05)$, com aumento do teor de minerais, ocorreram em razão do maior período e temperatura de armazenamento, sendo constatadas estas alterações entre as temperaturas aos 180 dias e a $35^{\circ} \mathrm{C}$ para a variedade BR-IRGA 410; a partir dos 60 dias e a 20 e $35^{\circ} \mathrm{C}$ para a variedade IRGA 416; e entre as temperaturas aos 120 e 180 dias para a variedade IRGA 417.
Tais resultados sugerem que o armazenamento por maior tempo e em maiores temperaturas favorece a presença de minerais no interior dos grãos de arroz. Embora o incremento dos minerais no arroz armazenado não tenha sido relatado por nenhum outro trabalho, deve estar relacionado à migração destes compostos das camadas externas para o endosperma em decorrência da atividade enzimática que os requer como cofatores enzimáticos. Variações no conteúdo mineral dos grãos de arroz são principalmente influenciadas pelas condições de cultivo, incluindo fertilização e condições do solo, tipo de processamento e características varietais (JULIANO, 1985; MARSHALL; WADSWORTH, 1994).

De acordo com os dados da Tabela 1, as variedades estudadas, BR-IRGA 410, IRGA 416 e IRGA 417, inicialmente apresentaram teores proteicos de 8,30; 9,18 e 9,51\%, respectivamente. As variações nestes valores foram constatadas apenas para a variedade BR-IRGA 410, com valores significativamente superiores $(\mathrm{P}<0,05)$ no decorrer do período de armazenamento nas três temperaturas testadas.

O conteúdo proteico do arroz polido é de aproximadamente 7,5\% (grão cru e base úmida), mas pode oscilar entre 5 e 13\%, conforme características varietais. As principais frações proteicas que constituem a proteína do arroz são a albumina, globulina, prolamina e glutenina, esta última representando de 70 a $80 \%$ do total, com $16,8 \%$ de nitrogênio e teores consideráveis do aminoácido essencial, e limitante, lisina (NAVES, 2007). Embora a proteína não seja o componente mais usual para predizer a qualidade culinária do arroz, variedades de arroz com baixo conteúdo proteico geralmente apresentam maior adesividade entre os grãos cozidos (JULIANO, 1985). 


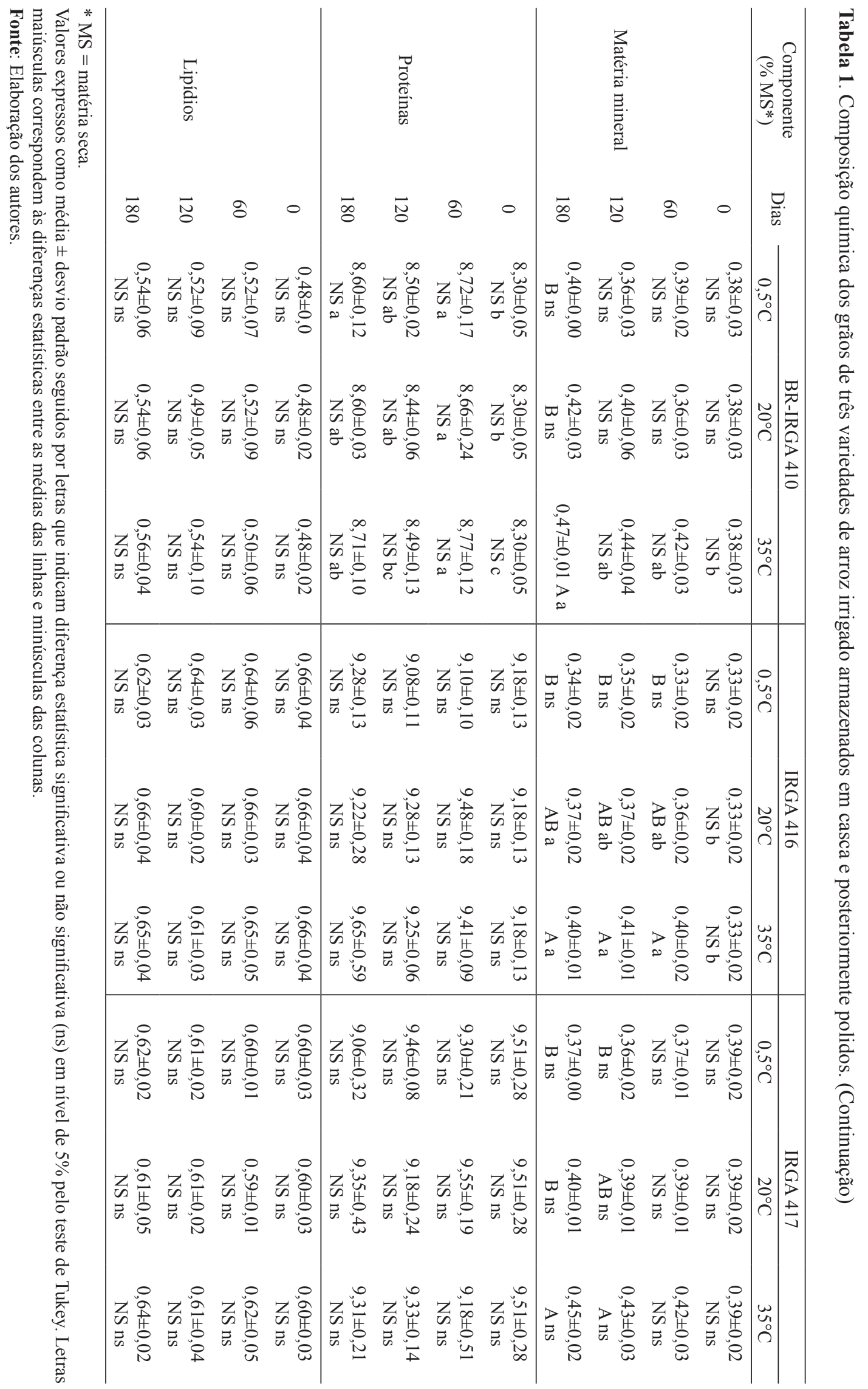




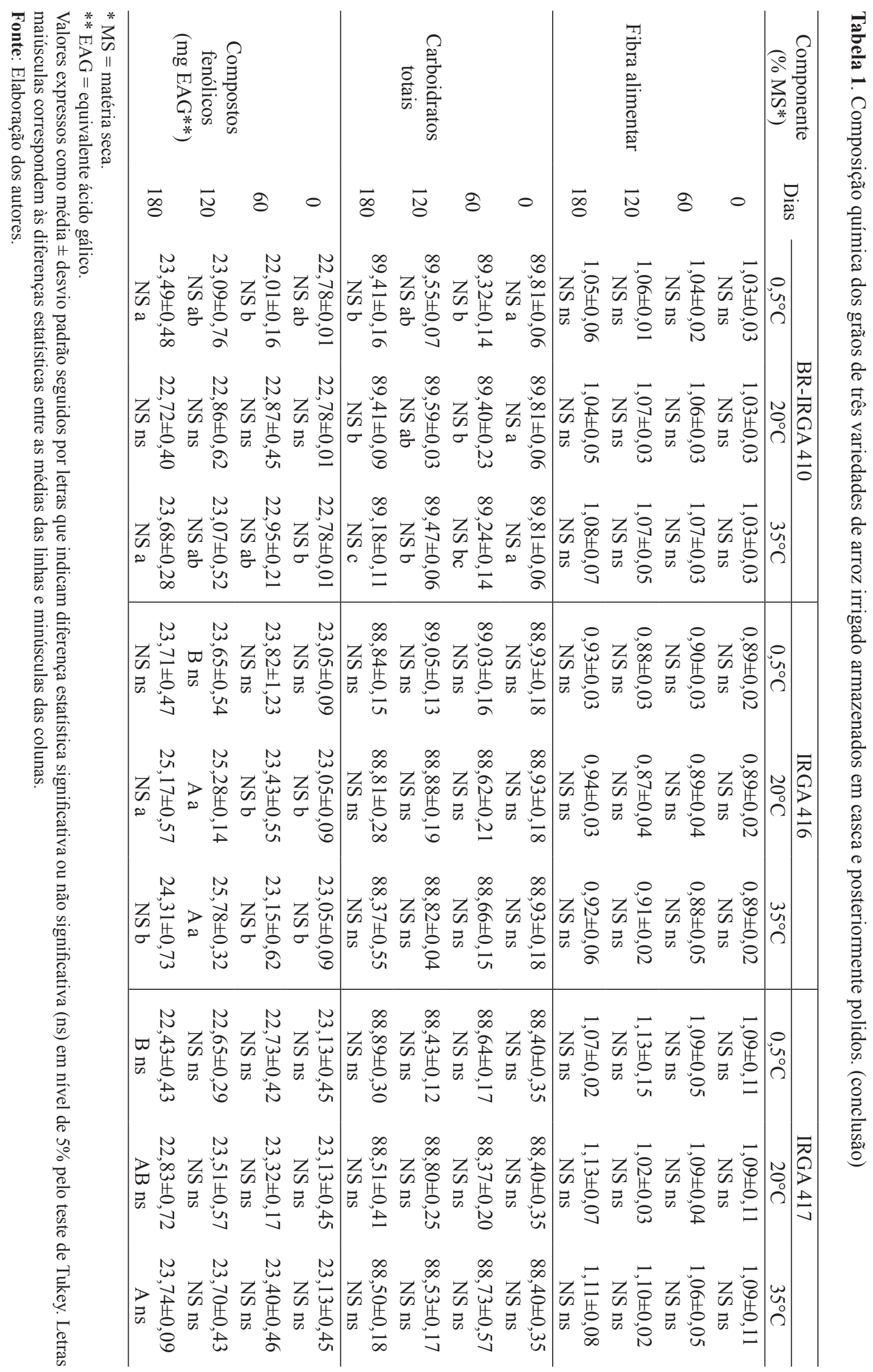


Diversos trabalhos relataram que o conteúdo proteico do arroz não é alterado no armazenamento, mas que as proteínas apresentam aumento no número de ligações dissulfeto entre as cadeias polipeptídicas, promovendo maior interação proteica, expressivo aumento no peso molecular, redução na solubilidade e amenização de aroma sulfuroso indesejável, característico no arroz novo (CHRASTIL, 1990; CHRASTIL; ZARINS, 1992; ZHOU et al., 2002). Contraditoriamente, é relatado aumento de aminoácidos livres, principalmente nas camadas externas do grão, que servem de substratos para reações de Maillard, com alterações de cor no arroz armazenado (DHALIWAL; SEKHON; NAGI, 1991; ZHOU et al., 2002).

Nas amostras armazenadas, os teores de lipídios e fibra alimentar não foram alterados significativamente $\quad(\mathrm{P}>0,05) \quad$ durante $\mathrm{O}$ armazenamento, sendo constatados valores inferiores de lipídios na variedade BR-IRGA 410 e de fibra alimentar na IRGA 416 (Tabela 1).

Os conteúdos de lipídios e fibra no arroz polido são baixos, normalmente menos de $1 \%$, visto que estes componentes encontram-se nas camadas periféricas do grão, sendo removidos no beneficiamento. Cerca de $80 \%$ dos lipídios do grão de arroz estão no farelo, que depois de polido mantém aproximadamente 20\% dos lipídios, constituídos principalmente dos ácidos graxos insaturados oleico e linoleico. Quanto à fibra alimentar, embora a maior parte deste componente seja removida no polimento, a fração remanescente é composta principalmente de hemicelulose e pectina (NAVES, 2007).

A contribuição dos lipídios na qualidade culinária ainda não é bem esclarecida, pois quando removidos previamente à cocção, não afetam a soltabilidade do arroz cozido, porém quando removidos previamente ao armazenamento, retardam o processo de envelhecimento, com menor alteração de propriedades viscoamilográficas, aroma e cor nos grãos (ZHOU et al., 2002).

Alguns trabalhos que constataram redução do conteúdo lipídico do arroz durante o armazenamento, justificaram pela formação de produtos da oxidação lipídica, tais como propanal, pentanal e hexanal, que caracterizam o aroma de arroz velho. Dentre estes compostos, o hexanal, formado a partir do ácido linoleico, é considerado o principal responsável pelo aroma de arroz velho (TSUZUKI; TANAKA; SHIDA, 1981).

A estabilidade dos lipídios no arroz é comprometida pela ação de fosfolipases, injúrias mecânicas e alta temperatura, que destroem as membranas celulares, iniciando a hidrólise em ácidos graxos livres e glicerol pela ação das lipases. Outro processo que envolve alterações nos lipídios durante o armazenamento do arroz é a oxidação em hidroperóxidos, mais comuns nas camadas externas dos grãos, onde ocorre menor concentração do amido, já que este se associa aos lipídios e exerce um efeito protetor contra a hidrólise e oxidação (ZHOU et al., 2002).

Os nutrientes não estão uniformemente distribuídos no grão, nas camadas externas ocorrem maiores concentrações de proteínas, lipídios, fibras, minerais e vitaminas, enquanto que o endosperma é composto basicamente por carboidratos (cerca de $80 \%$ ), sendo que quase a totalidade destes carboidratos é representada por amido. Desta maneira, o polimento do grão integral provoca perdas mais consideráveis dos nutrientes das camadas externas (NAVES, 2007; WALTER, 2009).

Pode-se observar na Tabela 1, que os teores de carboidratos totais foram alterados significativamente $(\mathrm{P}<0,05)$ apenas para a variedade BR-IRGA 410, na qual se observou diminuição neste componente no decorrer do armazenamento nas três temperaturas testadas. Esta diminuição provavelmente está atrelada ao incremento no conteúdo proteico observado para os grãos desta variedade.

No entanto, a alteração no teor de carboidratos totais para a variedade BR-IRGA 410 não refletiu em alteração no teor de amido disponível. Inicialmente, 
os teores de amido disponível foram de 87,38; 86,23 e 86,79 para as variedades IRGA 410, IRGA 416 e IRGA 417, respectivamente, e não apresentaram variação significativa $(\mathrm{P}>0,05)$ no decorrer do armazenamento (Tabela 2).

O amido no arroz é formado por dois tipos de polímeros, amilose e amilopectina. O primeiro, correspondente à fração linear, é de grande interesse no processamento e tecnologia do arroz e diretamente relacionada com a qualidade culinária do arroz, sendo que a proporção presente no grão é utilizada para predizer seu comportamento culinário: quanto maior, mais secos e soltos apresentam-se os grãos cozidos (CUEVAS; FITZGERALD, 2008; NAVES, 2007). Já a maciez e aglutinação dos grãos cozidos são inversamente correlacionadas com o teor de amilose, sendo que baixo teor de amilose confere arroz aguado no cozimento (BASSINELLO; ROCHA; COBUCCI, 2004).

Quantidades intermediárias e altas de amilose definem a aceitabilidade culinária de diversas variedades de arroz, no caso das variedades de arroz não glutinoso, estas constituem a maior parte do arroz consumido no mundo, apresentando entre 8 e $37 \%$ de amilose, embora a maioria tenha de 13 a $32 \%$ (JULIANO, 1985; MARSHALL; WADSWORTH, 1994).

As variedades de arroz, IRGA 416, BRIRGA-410 e IRGA 417, são caracterizadas por apresentarem conteúdo de amilose baixo (até 19\%), intermediário (entre 20 e 24\%) e alto (mais de 25\%), respectivamente (COFFMAN; JULIANO, 1987; STORCK, 2004). Os resultados expostos na Tabela 2 demonstram que, quanto ao teor de amilose, as variedades foram coerentes com a sua classificação.
O efeito do armazenamento sobre os teores de amilose foi constatado em maiores períodos e temperaturas de armazenamento, com aumento significativo $(\mathrm{P}<0,05)$ para a variedade $\mathrm{BR}-$ IRGA 410 no decorrer do armazenamento e, principalmente, em maiores temperaturas. Já a variação do conteúdo de amilose na variedade IRGA 416 foi verificada no armazenamento a $35^{\circ} \mathrm{C}$ e aos 180 dias de armazenamento entre as diferentes temperaturas. Enquanto que a variedade IRGA 417 demonstrou maior conteúdo de amilose para o armazenamento a $35^{\circ} \mathrm{C}$, mas apenas após 180 dias.

O discreto aumento nos conteúdos de amilose sugere que os grãos sofreram alterações na conformação estrutural do grânulo de amido, com aumento das interações entre as cadeias de amido, deixando o grânulo mais organizado. De acordo com Zhou et al. (2002), no armazenamento do arroz não ocorrem significativas alterações nos conteúdos de amido e amilose, pois pequenas alterações na proporção amilose/amilopectina, muitas vezes sequer são constatadas pelos métodos analíticos convencionais.

O teor de amido resistente também aumentou no armazenamento das variedades BR-IRGA 410 e IRGA 417 a $35^{\circ} \mathrm{C}$, com distinção entre as temperaturas de armazenamento aos 120 e 180 dias, enquanto que não foram observadas alterações para a variedade IRGA 416 (Tabela 2). 


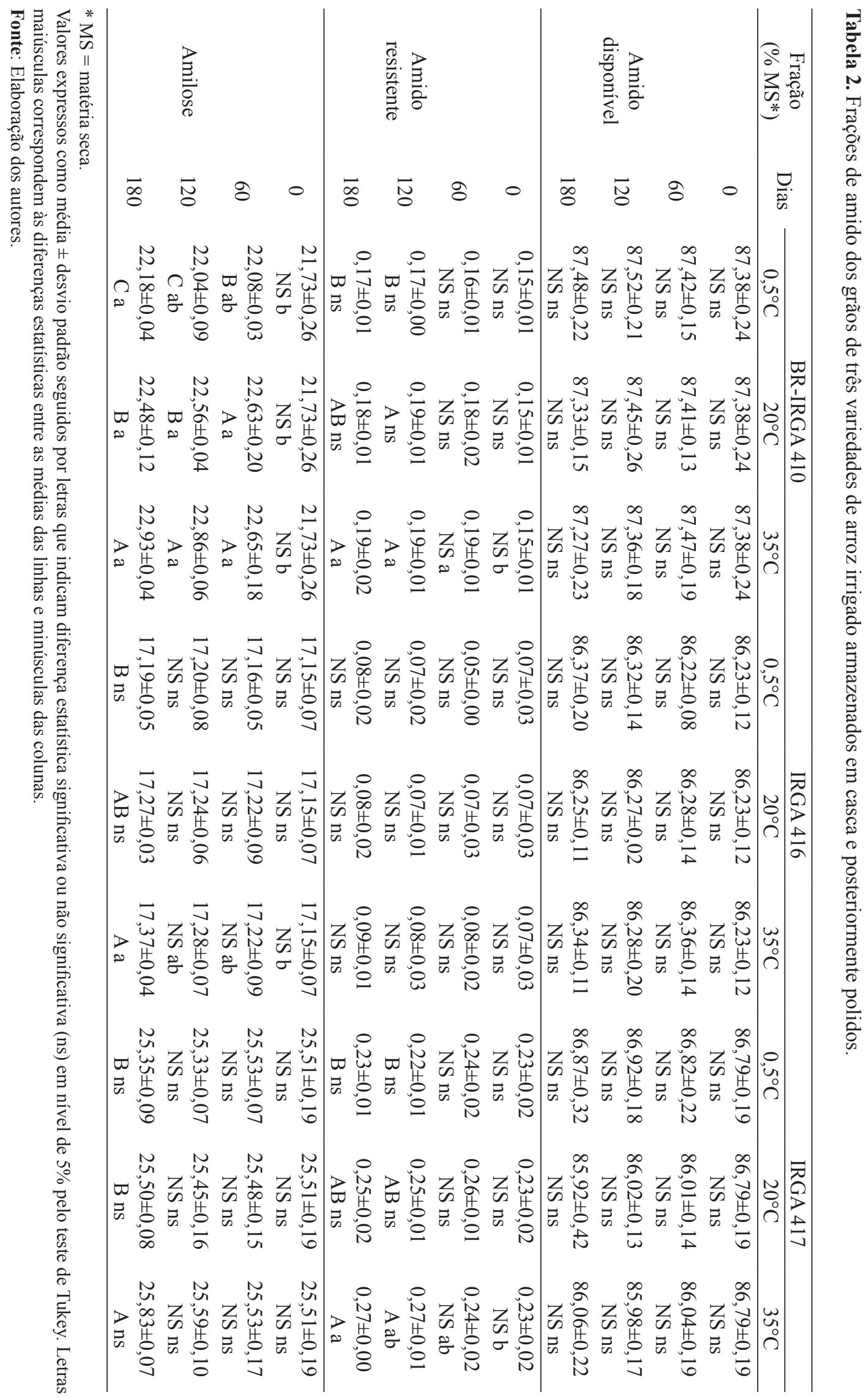


O aumento nos teores de amido resistente sugerem a ocorrência de alterações estruturais e maior insolubilidade dos constituintes dos grãos, devido às interações entre as cadeias de amido, de ácidos graxos com amido e menor acesso para enzimas hidrolíticas. Rehman (2006) descreveu que as alterações estruturais nos grãos os tornam mais resistentes à hidrólise, principalmente no armazenamento por longos períodos e maiores temperaturas, provocando redução de açúcares solúveis, da digestibilidade proteica e do amido.

Independente das alterações no teor amido resistente no decorrer do período de armazenamento, constatou-se que quanto maior o teor de amilose, também foi maior o teor de amido resistente. Constatação semelhante foi descrita por Helbig et al. (2007), que relataram maior teor de amido resistente no grão cru para amostras com maior teor de amilose; embora também constataram que os grãos com menor teor de amilose, após cozidos e resfriados, tiveram maior aumento proporcional de amido resistente.

O amido resistente é denominado como a soma do amido e produtos de sua degradação não absorvidos no intestino delgado de indivíduos saudáveis. A esta fração de amido, têm-se atribuído diversos efeitos benéficos no organismo humano, onde compartilham de efeitos da fração insolúvel, sendo também fermentado pela microflora com produção de gases $\left(\mathrm{CO}_{2}, \mathrm{H}_{2}\right.$ e $\left.\mathrm{CH}_{4}\right)$ e ácidos graxos de cadeia curta (butirato, propionato e acetato) que auxiliam na manutenção do epitélio intestinal, prevenção de doenças e supressão de células cancerosas (WALTER; SILVA; PERDOMO, 2005).

A concentração de compostos fenólicos das amostras armazenadas variou entre 22,01 e 25,78 $\mathrm{mg} \% \mathrm{EAG}$, com tendência de aumento no decorrer do período de armazenamento e em maiores temperaturas, mas de maneira significativa $(\mathrm{P}<0,05)$ para a variedade BR-IRGA 410 armazenada a $0,5 \mathrm{e}$ $35^{\circ} \mathrm{C}$; IRGA 416 a 20 e $35^{\circ} \mathrm{C}$, com diferença entre as temperaturas de armazenamento aos 120 dias; e IRGA 417 aos 180 dias de armazenamento, com maior teor de compostos fenólicos nas amostras mantidas a $35^{\circ} \mathrm{C}$, seguidas das de 20 e $0,5^{\circ} \mathrm{C}$ (Tabela 1).

Tais valores são semelhantes aos descritos por Walter (2009), que encontrou cerca de 25 mg\% EAG na matéria seca de grãos de arroz polidos. Outras pesquisas indicam que a distribuição de compostos fenólicos muda durante o armazenamento de arroz, de maneira geral com aumento no conteúdo de ácidos fenólicos em maiores períodos e temperaturas de armazenamento, provavelmente como resultado da liberação enzimática ou não enzimática de ácidos fenólicos ligados, que também interferem nas características culinárias do arroz mais velho (TSUGITA; OHTA; KATO, 1983; ZHOU et al., 2004).

Os compostos fenólicos são metabólitos secundários dos vegetais, com diferentes funções nas plantas. Eles podem ser classificados em diferentes grupos, sendo os ácidos fenólicos, os flavonóides e os taninos os principais na dieta (KING; YOUNG, 1999). No arroz, diversos compostos fenólicos já foram identificados, com destaque para os ácidos hidroxicinâmicos, representados principalmente pelo ácido ferrúlico e p-coumarínico (TIAN; NAKAMURA; KAYAHARA, 2004; ZHOU et al., 2004). Outros compostos identificados no arroz incluem os ácidos vanílico, siríngico, caféico, gálico, protocatéquico, hidroxibenzóico, sinápico e clorogênico, e os ésteres 6'-O-(E)-feruloilsacarose, 6'-O-(E)-sinapoilsacarose e $\gamma$-orizanol (TIAN; NAKAMURA; KAYAHARA, 2004; ZHOU et al., 2002; ZHOU et al., 2004).

Além de reconhecidas funções nos vegetais, pesquisas têm demonstrado o efeito benéfico de compostos fenólicos de diferentes fontes, inclusive do arroz, na saúde humana. Este efeito decorre de sua ação antioxidante, auxiliando na prevenção de danos celulares e de doenças crônicas, que incluem doenças cardiovasculares, envelhecimento, diabetes e câncer (XIA et al., 2003; HYUN; CHUNG, 2004; 
WALTER, 2009). Neste sentido, o arroz, sendo um dos principais alimentos na dieta de grande parte da população, pode representar importante fonte de antioxidantes ingerida diariamente, embora a concentração desses compostos seja afetada pelo processamento, já que estão associados principalmente ao pericarpo, que é removido durante o processo para obtenção do grão polido (HU et al., 2003; ZHOU et al., 2004; WALTER, 2009).

De maneira geral, os resultados da composição química dos grãos reproduzem alguns trabalhos que buscaram evidências sobre as alterações na qualidade culinária do arroz armazenado e observaram variações muito pequenas em condições normais de armazenamento (MARSHALL; WADSWORTH, 1994; ZHOU et al., 2002).

As dimensões dos grãos das três variedades de arroz testadas foram influenciadas significativamente $(\mathrm{P}<0,01)$ pela variedade, tempo e temperatura de armazenamento. A alteração proporcional e taxa de elongação aumentaram progressivamente, de maneira mais pronunciada no armazenamento a $35^{\circ} \mathrm{C}$ e mais discreta a $0,5^{\circ} \mathrm{C}$, com valores maiores de alteração proporcional para a variedade IRGA 417, enquanto que as taxas de elongação foram bastante semelhantes entre as temperaturas e variedades (Figura 1).

Já a elongação efetiva, que corresponde à diferença de comprimento entre o arroz cozido e cru, também apresentou aumento mais pronunciado em maiores períodos e temperaturas de armazenamento, mais expressivo para a variedade IRGA 416, com aparente estabilização a partir da metade do período de armazenamento a $35^{\circ} \mathrm{C}$, seguido das variedades IRGA 417 e BR-IRGA 410 (Figura 1).
Aliado ao aumento em comprimento, no decorrer do armazenamento, os grãos de arroz cozidos ficaram mais inteiros e com melhor aparência. Alguns trabalhos que avaliaram as alterações dimensionais de grãos de arroz descreveram resultados semelhantes aos obtidos neste estudo e atribuíram às características varietais, composição química, temperatura, método de preparo e, principalmente, ao período de armazenamento do arroz, sugerindo que o aumento no comprimento dos grãos cozidos é uma característica marcante do envelhecimento deste cereal e decorrente das alterações estruturais intrínsecas (SOOD; SIDDIQ, 1980; FARUQ et al., 2003).

As propriedades viscoamilográficas representam os índices mais sensíveis do processo de envelhecimento do arroz (SOWBHAGYA; BHATTACHARYA, 2001). Até o momento, os dados viscoamilográficos relatados durante o armazenamento do arroz são bastante inconsistentes, pois apresentam alterações mais pronunciadas nos primeiros períodos e estabilização, ou ainda, alterações contrárias às observadas no início do armazenamento (ZHOU et al., 2003). 


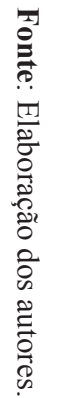

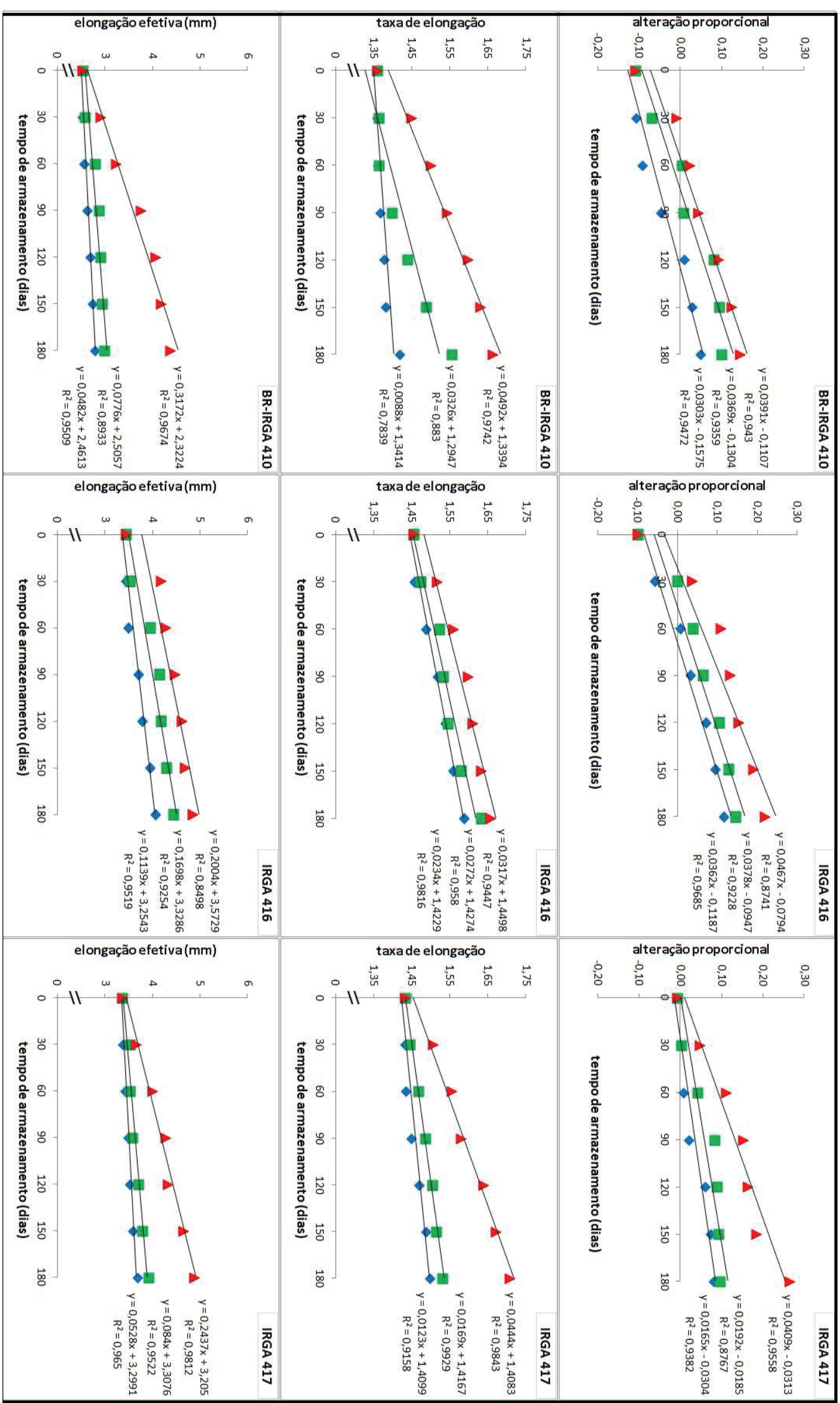

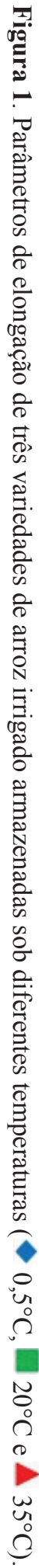


Os parâmetros viscoamilográficos avaliados por RVA no decorrer do armazenamento foram todos significativamente $(\mathrm{P}<0,01)$ influenciados pela variedade, tempo e temperatura de armazenamento. Conforme gráficos apresentados na Figura 2, os parâmetros de temperatura de pasta e tempo de pico tiveram comportamento gráfico semelhante. Reservadas as diferenças entre as variedades, as amostras armazenadas a 0,5 e $20^{\circ} \mathrm{C}$ apresentaram apenas diminuição nestes parâmetros, enquanto que redução seguida de aumento foi observada nas amostras mantidas a $35^{\circ} \mathrm{C}$. Estas semelhanças estão relacionadas, pois quanto menor a temperatura para a gelatinização do amido, menor o tempo para atingir o pico de viscosidade, e vice versa.

Outros trabalhos que avaliaram as propriedades viscoamilográficas do arroz armazenado também relataram este comportamento nos parâmetros de temperatura de pasta e tempo de pico, atribuindo à presença, orientação e natureza dos lipídios e proteínas da superfície dos grânulos de amido, que quando assumem uma forma mais organizada, requerem maior temperatura e tempo para gelatinização (SOWBHAGYA; BHATTACHARYA, 2001; ZHOU et al., 2003). A interação entre as cadeias de proteínas, com formação de ligações dissulfeto, diminui sua interação com o amido e, inicialmente, facilita a gelatinização do amido do arroz armazenado (SODHI et al., 2003; TULYATHAN; LEEHARATANALUK, 2007).

Para o parâmetro de viscosidade, normalmente é relatado aumento e estabilização durante o armazenamento do arroz, embora alguns trabalhos que avaliaram o comportamento viscoamilográfico do arroz por alguns anos, a partir de cinco anos, também relataram redução da viscosidade do arroz armazenado (HAMAKER; SIEBENMORGEN; DILDAY, 1993; SOWBHAGYA; BHATTACHARYA, 2001; ZHOU et al., 2002).
O aumento da viscosidade de pico (Figura 2) foi observado nas três variedades de arroz, principalmente em maiores períodos e temperaturas de armazenamento, porém as diferenças varietais ficaram mais evidentes na viscosidade final (Figura 3), onde as variedades com maior teor de amilose apresentaram maior viscosidade final, principalmente no armazenamento a $35^{\circ} \mathrm{C}$.

Variedades com maior teor de amilose são caracterizadas por apresentar maior viscosidade, temperatura de pasta e tempo de pico, pois a conformação estrutural do grânulo é mais organizada (CUEVAS; FITZGERALD, 2008). A pronunciada alteração na viscosidade é um efeito do envelhecimento do arroz associado à interação do amido, principalmente amilose, com outros componentes do grão, em especial com ácidos graxos, sendo que o aumento inicial da viscosidade também é relacionado com o declínio da atividade da enzima $\alpha$-amilase (PENTEADO, 1990; SOWBHAGYA; BHATTACHARYA, 2001; ZHOU et al., 2003).

A quebra é considerada o parâmetro primário do viscograma, com tendência de diminuir no envelhecimento do arroz, já que os grânulos de amido do arroz armazenado são mais resistentes, organizados e estáveis à ruptura durante a gelatinização (NOOMHORM; KONGSEREE; APINTANAPONG, 1997; ZHOU et al., 2002; ZHOU et al., 2003). No entanto, diversos estudos observaram um aumento na quebra nos primeiros meses de armazenamento do arroz, justificado como um rearranjo entre os constituintes dos grãos, com posterior diminuição e estabilização deste parâmetro na sequência do envelhecimento do arroz (SOWBHAGYA; BHATTACHARYA, 2001; ZHOU et al., 2002; ZHOU et al., 2003). 


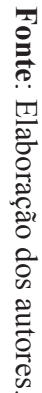

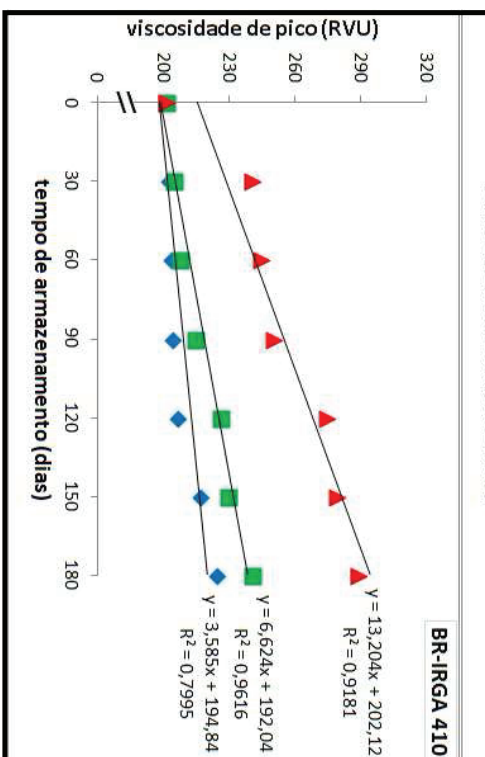

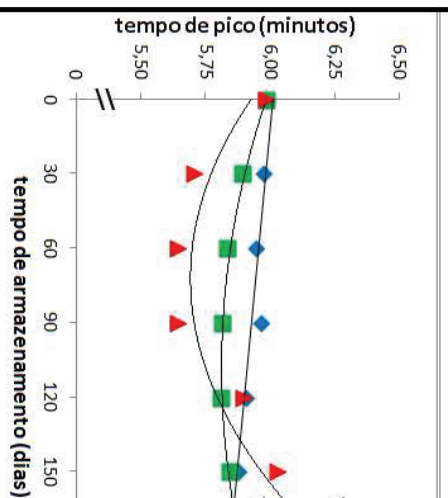

viscosidade de pico(RVU)

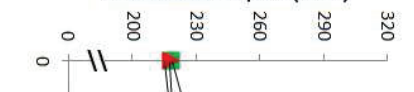

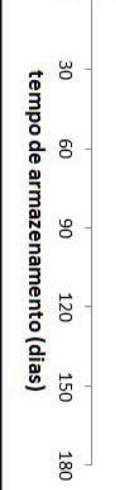

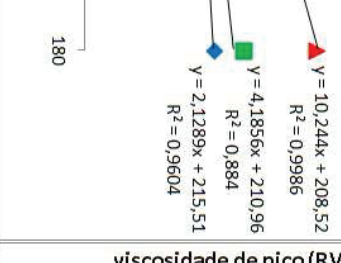
viscosidade de pico(RVU)
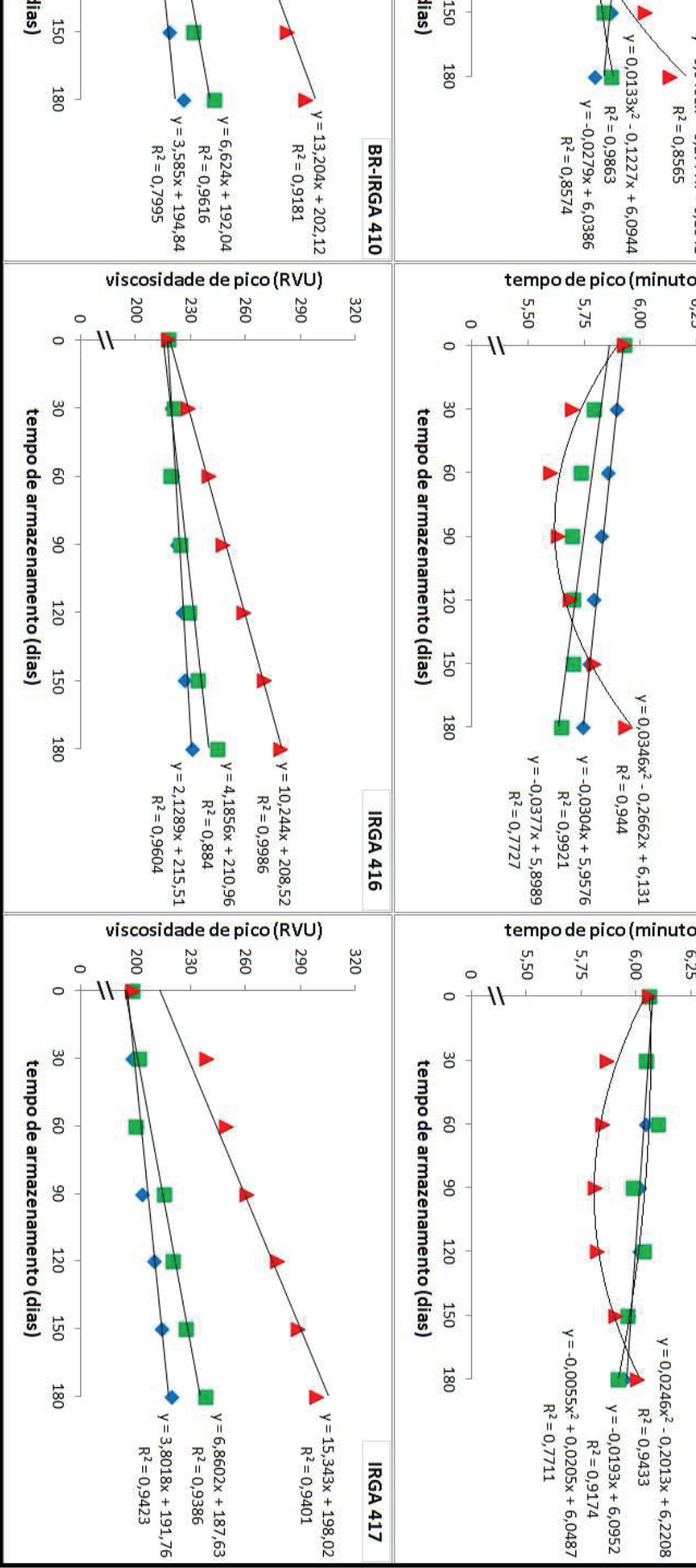

品

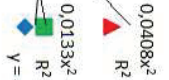

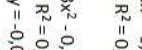

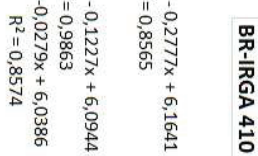

tempode pico(minutos)

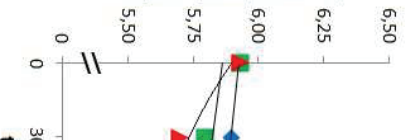

\section{(1)}
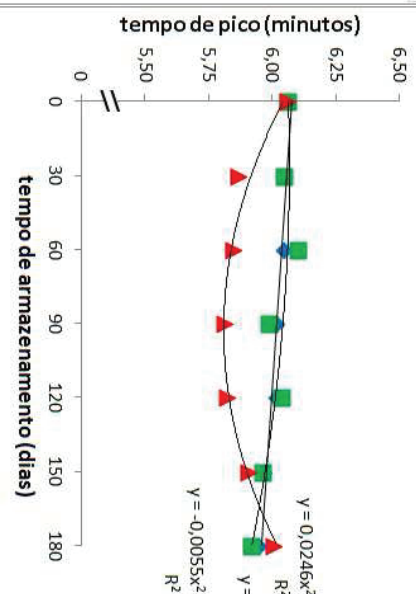

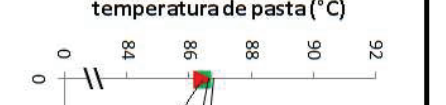

(2)

을

กำ

$\square$

응

○े

के

w

กุ?
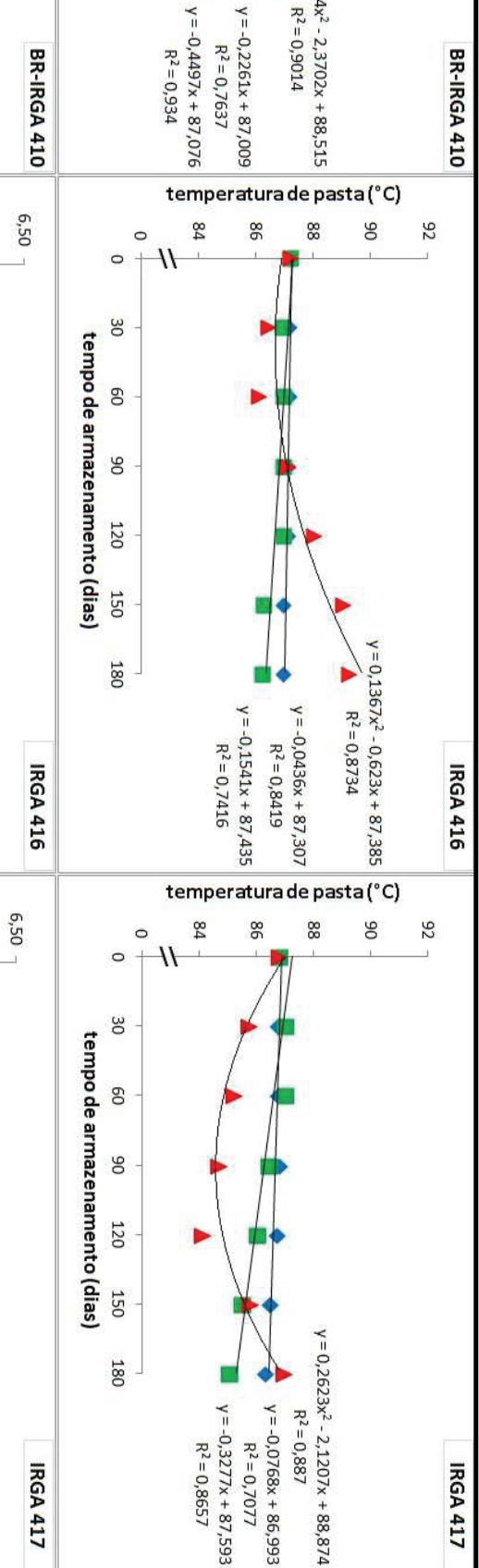


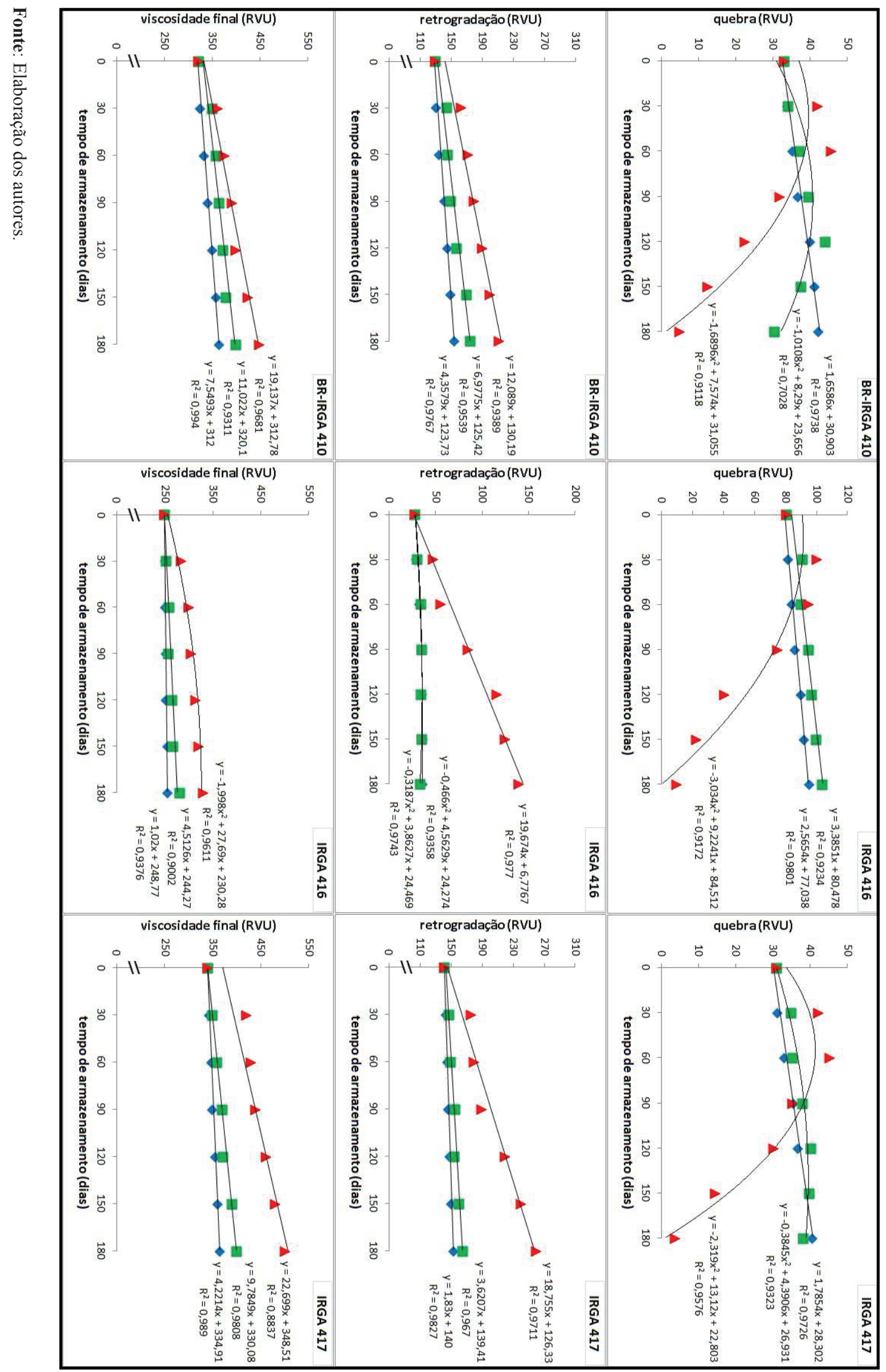

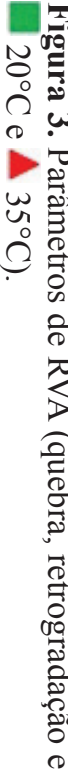

$\leq$

o

满

:

융.

:

के

:

$\Xi$

\%ั

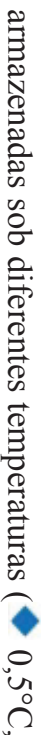


Nas amostras armazenadas a $35^{\circ} \mathrm{C}$, onde o processo de envelhecimento foi favorecido, este comportamento foi bastante evidente, enquanto que nas amostras armazenadas a 0,5 e $20^{\circ} \mathrm{C}$ observouse apenas aumento da quebra (Figura 3), o que não deve ser interpretado como comprometedor das características culinárias, pois, provavelmente, se o período de armazenamento fosse prolongado estas amostras também apresentariam redução na quebra.

Han e Hamaker (2001) avaliaram dez variedades de arroz e estabeleceram uma relação da quebra com o teor de amilose: quanto maior o teor de amilose, menor a quebra. Por sua vez, também nos gráficos demonstrados na Figura 3, é possível observar que inicialmente as variedades com maior teor de amilose (BR-IRGA 410 e IRGA 417) apresentaram quebra menor que a variedade IRGA 416, porém o armazenamento a $35^{\circ} \mathrm{C}$ atribuiu valores de quebra semelhantes a partir de 150 dias.

A retrogradação é considerada o parâmetro mais tradicional da análise viscoamilográfica, com tendência a aumentar no arroz armazenado (PERDON et al., 1999; SOWBHAGYA; BHATTACHARYA, 2001). Os resultados descritos na Figura 3 demonstram este comportamento, com aumento progressivo nos valores de retrogradação no decorrer do período de armazenamento, principalmente em maiores temperaturas e, de maneira mais expressiva, para as variedades com maior teor de amilose.

\section{Conclusão}

As alterações na composição química dos grãos, quando constatadas, foram bastante sutis e não determinaram as alterações nos parâmetros de elongação, viscoamilográficos e, consequentemente, culinários das variedades de arroz estudadas.

O aumento em alguns componentes dos grãos (cinzas, compostos fenólicos, amilose e amido resistente), parâmetros de elongação e alterações nas propriedades viscoamilográficas foram mais expressivos a $35^{\circ} \mathrm{C}$, demonstrando que nesta temperatura o processo de envelhecimento é favorecido em relação às demais temperaturas testadas e confere qualidade culinária em menor tempo de armazenamento.

\section{Agradecimentos}

Ao Instituto Rio Grandense do Arroz pela concessão das amostras e à empresa RiceTec Sementes pelo auxílio com as análises de RVA.

\section{Referências}

AMERICAN ASSOCIATION OF CEREAL CHEMISTS - AACC. Approved methods. $10^{\text {th }}$ ed. Saint Paul: AACC, 2000.

ASSOCIATION OF OFFICIAL ANALYTICAL CHEMISTS - AOAC. Official methods of analysis. $17^{\text {th }}$ ed. Gaithersburg: AOAC, 2000.

BASSINELLO, P. Z.; ROCHA, M. S.; COBUCCI, R. M. A. Avaliação de diferentes métodos de cocção de arroz de terras altas para teste sensorial. Santo Antônio de Goiás: Embrapa Arroz e Feijão, dez. 2004. 8 p. (Comunicado Técnico Online, 84).

BLIGH, E. C.; DYER, W. J. A rapid method of total lipid extraction and purification. Canadian Journal of Biochemistry and Physiology, Ottawa, v. 37, n. 8, p. 911917, aug. 1959.

CHRASTIL, J. Protein-starch interaction in rice grains. Influence of storage on oryzenin and starch. Journal of Agricultural and Food Chemistry, Easton, v. 38, n. 9, p, 1804-1809, sept. 1990.

CHRASTIL, J.; ZARINS, Z. M. Influence of storage on peptide subunit composition of rice oryzenin. Journal of Agricultural and Food Chemistry, Easton, v. 40, n. 6, p, 927-930, jun. 1992.

COFFMAN, W. R.; JULIANO, B. O. Rice. In: OLSON, R. A.; FREY, K. J. (Ed.). Nutritional quality of cereal grains: genetic and agronomic improvement. Madison: American Society of Agronomy, 1987. p. 101-131.

CUEVAS, R. P.; FITZGERALD, M. Linking starch structure to rice cooking quality. Irrigation Research and Extension Committee Farmer's Newsletter, n. 177, p. 1617, 2007, 2008. Disponível em: <http://www.irec.org.au/ farmer_f $/$ pdf_177/Linking $\%$ 20starch $\% 20$ structure $\% 20$ to $\% 20$ rice $\% \overline{2}$ cooking $\% 20$ quality.pdf $>$. Acesso em: 18 ago. 2009. 
DHALIWAL, Y. S.; SEKHON, K. S.; NAGI, H. P. S. Enzymatic activities and rheological properties of stored rice. Cereal Chemistry, Saint Paul, v. 68, n. 1, p. 18-21, jan. 1991.

ELIAS, M. C. Pós-colheita de arroz: secagem, armazenamento e qualidade. Pelotas: Editora e Gráfica Universitária, 2007. 437 p.

FARUQ, G.; MOHAMAD, O.; HADZIM, M.; MEISNER, C. A. Optimization of aging time and temperature for four malaysian rice cultivars. Pakistan Journal of Nutrition, Faisalabad, v. 2, n. 3, p. 125-131, may/jun. 2003.

HAMAKER, B. R.; SIEBENMORGEN, T. J.; DILDAY, R. H. Ageing of rice in the first six mounths after harvest. Arkansas Farm Research, New York, v. 43, n. 1, p. 8-9, jan./feb. 1993.

HAN, X. Z.; HAMAKER, B. R. Amylopectin fine structure and rice starch paste breakdown. Journal of Cereal Science, Oxford, v. 34, n. 3, p. 279-284, nov. 2001.

HELBIG, E.; ROMANO, C. M.; RADÜNZ, A. L.; RUTZ, D.; DIAS, A. R. G. Efeitos da amilose e do processamento na formação e estabilidade do amido resistente em arroz. Brazilian Journal of Food Technology, Campinas, v. 10, n. 4, p. 296-301, out./dez. 2007.

HU, C.; ZAWISTOWSKI, J.; LING, W.; KITTS, D. D. Black rice (Oryza sativa L. indica) pigmented fraction suppresses both reactive oxygen species and nitric oxide in chemical and biological model systems. Journal of Agricultural and Food Chemistry, Easton, v. 51, n. 18, p. 5271-5277, aug. 2003.

HYUN, J. W.; CHUNG, H. S. Cyanidin and malvidin from Oryza sativa cv. Heugjinjubyeo mediate cytotoxicity against human monocytic leukemia cells by arrest of G2/M phase and induction of apoptosis. Journal of Agricultural and Food Chemistry, Easton, v. 52, n. 8, p. 2213-2217, apr. 2004.

IQBAL, S.; BHANGER, M. I.; ANWAR, F. Antioxidant properties and components of some commercially available varieties of rice bran in Pakistan. Food Chemistry, Oxford, v. 93, n. 2, p. 265-272, nov. 2005.

JULIANO, B. O. Rice: chemistry and technology. Saint Paul: American Association of Cereal Chemists, 1985. $774 \mathrm{p}$.

KING, A.; YOUNG, G. Characteristics and occurrence of phenolic phytochemical. Journal of the American Dietetic Association, New York, v. 99, n. 2, p. 213-218, feb. 1999.
MARSHALL, W. E.; WADSWORTH, J. I. Rice science and technology. New Orleans: Marcel Dekker, 1994. 470 p.

MARTÍNEZ, C.; CUEVAS-PEREZ, F. Evaluación de la calidad culinária y molinera del arroz. Cali: Centro Internacional de Agricultura Tropical, 1989. 75 p.

NAVES, M. M. V. Características químicas e nutricionais do arroz. Boletim do Centro de Pesquisa de Processamento de Alimentos, Curitiba, v. 25, n. 1, p. 5160, jan./jul. 2007.

NOOMHORM, A.; KONGSEREE, N.; APINTANAPONG, N. Effect of ageing on the quality of glutinous rice crackers. Cereal Chemistry, Saint Paul, v. 74, n. 1, p. 12-15, jan./feb. 1997.

PENTEADO, M. F. Qualidade de arroz (Oryza sativa L.), armazenado em atmosfera modificada, em silo subterrâneo. 1990. Dissertação (Mestrado em Engenharia Agrícola) - Universidade Estadual de Campinas, Campinas.

PERDON, A. A.; SIEBENMORGEN, T. J.; BUESCHER, R. W.; GBUR, E. E. Starch retrogradation and texture of cooked milled rice during storage. Journal of Food Science, Malden, v. 64, n. 5, p. 828-832, sept. 1999.

PÉREZ-JIMÉNEZ, J.; SAURA-CALIXTO, F. Literature data may underestimate the actual antioxidant capacity of cereals. Journal of Agricultural and Food Chemistry, Easton, v. 53, n. 12, p. 5036-5040, jun. 2005.

REHMAN, Z. U. Storage effects on nutritional quality of commonly consumed cereals. Food Chemistry, Oxford, v. 95 , n. 1 , p. 53-57, mar. 2006.

SINGLETON, V. L.; ORTHOFER, R.; LAMUELARAVENTÓS, R. M. Analysis of total phenols and other oxidation substrates and antioxidants by means of FolinCiocalteau reagent. Methods in Enzymology, Oxford, v. 299, n. 1, p. 152-178, jan. 1999.

SODHI, N. S.; SINGH, N.; ARORA, M.; SINGH, J. Changes in physico-chemical, thermal, cooking and textural properties of rice during aging. Journal of Food Processing and Preservation, Malden, v. 27, n. 5, p. $387-$ 400, dec. 2003.

SOOD, G. B.; SIDDIQ, A. E. Studies on component quality attributes of basmati rice, Oryza sativa L. Z. Plant Breeding, Berlin, v. 84, n. 4, p. 294-301, 1980.

SOWBHAGYA, C. M.; BHATTACHARYA, K. R. Changes in pasting behaviour of rice during ageing. Journal of Cereal Science, Oxford, v. 34, n. 2, p. 115124, sept. 2001. 
STORCK, C. R. Variação na composição química de grãos de arroz submetidos a diferentes beneficiamentos. 2004. Dissertação (Mestrado em Ciência e Tecnologia dos Alimentos) - Universidade Federal de Santa Maria, Santa Maria.

TIAN, S.; NAKAMURA, K.; KAYAHARA, H. Analysis of phenolic compounds in white rice, brown rice, and germinated brown rice. Journal of Agricultural and Food Chemistry, Easton, v. 52, n. 15, p. 4808-4813, jul. 2004.

TSUGITA, T.; OHTA, T.; KATO, H. Cooking flavour and texture of rice stored under different conditions. Agricultural and Biological Chemistry, Tokyo, v. 47, n. 3, p. 543-549, mar. 1983.

TSUZUKI, E.; TANAKA, K.; SHIDA, S. Studies on the characteristics of scented rice. VIII. Effect of storage conditions on some fatty acid compositions and flavour components in rice grains. Kenkyu Hokoku Miyazaki Daigaku Nogakubu, Tokyo, v. 28, p. 31-37, 1981.

TULYATHAN, V.; LEEHARATANALUK, B. Changes in quality of rice (Oryza sativa L.) cv. Khao Dawk Mali 105 during storage. Journal of Food Biochemistry, Malden, v. 31, n. 3, p. 415-425, jun. 2007.
WALTER, M. Composição química e propriedades antioxidantes de grãos de arroz com pericarpo marromclaro, vermelho e preto. 2009. Tese (Doutorado em Agronomia) - Universidade Federal de Santa Maria, Santa Maria.

WALTER, M; SILVA, L. P.; PERDOMO, D. M. X. Amido disponível e resistente em alimentos: adaptação do método da AOAC 996.11. Alimentos e Nutrição, Araraquara, v. 16, n. 1, p. 39-43, jan./mar. 2005.

XIA, M.; LING, W. H.; MA, J.; KITTS, D. D.; ZAWISTOWSKI, J. Supplementation of diets with the black rice pigment fraction attenuates atherosclerotic plaque formation in apolipoprotein $\mathrm{E}$ deficient mice. Journal of Nutrition, Bethesda, v. 133, n. 3, p. 744-751, mar. 2003.

ZHOU, Z.; ROBARDS, K.; HELLIWELL, S.; BLANCHARD, C. Ageing of stored rice: changes in chemical and physical attributes. Journal of Cereal Science, Oxford, v. 35, n. 1, p. 65-78, jan. 2002.

. Effect of rice storage on pasting properties of rice flour. Food Research International, Oxford, v. 36, n. 6, p. 625-634, jan. 2003.

The distribution of phenolic acids in rice. Food Chemistry, Oxford, v. 87, n. 3, p. 401-406, sept. 2004. 